the eight-year period. Only $9(9 / 52 / 17.37 \%)$ CNS were fully met. The numbers of childbirth/CS/\% in HUAP were: 2008 (389/8/2.05\%); 2009 (373/6/1.60\%); $2010 \quad(442 / 4 / 0.90 \%)$; 2011 (508/0/0\%); 2012 (521/1/0.19\%); 2013 (640/9/1.40\%); 2014 (522/14/2.68\%); 2015 (422/10/2.37\%). Maternal age: 6 pregnant women (11.5\%) between 14 and 18 years, 25 (48.1\%) between 19 and 25 years, 18 (34.6\%) between 26 and 40 years and $3(5.8 \%)$ Ignored. About prenatal care: 10 pregnant women (19.2\%) performed in HUAP, 34 (65.4\%) in basic health units in Niterói and other cities in the state, and $8(15.4 \%)$ did not done. The diagnosis of maternal syphilis occurred during prenatal care in $37(71 \%)$ cases, in childbirth in $12(23 \%)$ and after childbirth in $3(6 \%)$. Only 11 partners (21.1\%) were treated. Forty-eight (92.3\%) newborns were treated appropriately. Cases evolutions: 46 (88.5\%) were still alive, $3(5.8 \%)$ were stillborn, $2(3.8 \%)$ evolved to postpartum death and $1(1.9 \%)$ was an abortion.

Conclusion The notification and complete padding of the CS's CNS is of crucial importance for CS control with the pregnant women and prenatal evaluation. We found many flaws for a federal university service.

\section{P3.115 PREVALENCE AND RISK FACTORS ASSOCIATED WITH BACTERIAL VAGINOSIS IN SOUTHERN MEXICO}

Karen Cortés Sarabia, Ana Karen Estrada Moreno, Miying Dessire Goméz Cervantes, Luz Del Carmen Alarcón Romero Eugenia Flores Alfaro, Amalia Vences Velázquez. Autonomous University of Guerrero, Chilpancingo, Mexico

\subsection{6/sextrans-2017-053264.350}

Introduction Bacterial vaginosis (BV) is the most common vaginal infection, characterised by a decrease in Lactobacilli and an increase in anaerobic bacteria mainly Gardnerella vaginalis, a variable Gram coccobacillus that is isolated in up to $98 \%$ of cases. The prevalence of this clinical entity is varied and the associated risk factors are: having multiple sexual partners, age, use of contraceptive methods, alcohol consumption, smoking habit, among others. The diagnosis of this clinical entity is important because of the multiple gyneco-obstetric complications associated with this clinical entity like abortion, infertility, ectopic pregnancies and the predisposition to acquire other sexually transmitted diseases such as herpes, HIV, HPV, and others.

Methods A total of 298 samples of vaginal swab from women between the ages of 16 to 65 years. The diagnosis of BV was performed using the Amsel and Nugent criteria, in which we evaluate the vaginal flow, $\mathrm{pH}$, amine test, the presence of clue cells and the quantification of bacterial morphotypes. The culture of Gardnerella vaginalis was performed in Columbia medium enriched with $10 \%$ of human blood and a specific supplement for the growth of this bacteria, for its identification we use oxidase, catalase and hippurate hydrolysis. The women who agreed to participate in the study signed an informed consent and the clinical and personal information was obtained through a survey. The results were analysed in the stata V.11 program.

Results We report a prevalence of BV of $10.4 \%$ in the population of Chilpancingo Guerrero in Mexico. The risk factors associated with this clinical entity were aged between 32 to 41 years (OR: $495 \% \mathrm{CI}=1.2-13.6 \mathrm{p}=0.025)$, having 2 to 3 sexual partners (OR: $3.495 \% \mathrm{CI} \quad 1.3-8.9 \quad \mathrm{P}=0.012)$ and smoking habit (OR: 3.4 95\% CI 1.1-10.6 p=0.039).
Conclusion The results obtained in this study provided information about the epidemiology of $\mathrm{BV}$, which contributed to the efective detection and treatment of this clinical entity.

\section{P3.116 IMPROVING ACCESS TO HIV DIAGNOSIS BY EXPANDING IMPLEMENTATION OF RAPID DIAGNOSTIC TESTS IN THE STATE OF SAO PAULO, BRAZIL (2006 TO 2016)}

Karina Wolffenbuttel, Márcia Fernandes dos Santos, Tânia Regina Corrêa de Souza, Ivone Aparecida de Paula, Maria Clara Gianna. STD/AIDS State Program, STD/AIDS Reference and Training Centre, São Paulo - SP, Brazil

\subsection{6/sextrans-2017-053264.351}

Issue Sao Paulo has 43 million inhabitants, 645 cities, 251.133 reported AIDS cases. Despite the HIV low prevalence in our state $(0.5 \%)$. The HIV rapid diagnostic testing method (RDT HIV) universal implementation is considered a very important strategy to increase access of vulnerable populations to HIV diagnosis together with other focused strategies. The goal was to implement the RDT HIV in at least one health public service in all 645 municipalities. In Brazil, we have the Health Unic System SUS as an universal public health system.

Description Between 2006-2016, around 500 trainers trained approximately 10.000 health professionals. From 2010 to 2016, the STD/AIDS Program Coordination trained 800 facilitators during the decentralisation process. In 2016586 municipalities implemented RDT HIV besides conventional testing (91\%); 60\% in primary care units. As proxy of HIV performance, we focus HIV annual campaigns carried out in the state since 2008 considering the majority adherence of municipalities (91\% in 2016) and health services. 7000 rapid diagnostic HIV tests in 2008;18 000 in 2009; 35000 in 2010; 40000 in 2011; 40000 in 2012; 156000 in 2013; 247000 in 2014; 251000 in 2015.

Lessons learned: Training of professionals through the training of trainers has boosted the implementation of HIV RDT. Monitoring RDT HIV implementation through five macroregional meetings was fundamental to find out and discuss local obstacles to offer access to HIV testing without having to schedule. Most vulnerable population for HIV continues to seek out ST/AIDS referral services for testing. Primary health care health workers have difficulty delivering positive HIV test results. Performing extra-mural actions is easier when the health unit has already implemented the test in its routine.

New steps Priorities for 2017: Continue the implementation process among all primary health care services. Expand and focus HIV testing In places of concentration and socialisation of more vulnerable groups such as gays and transvestites. Support outreach-testing activities by NGOs.

\section{P3.117 HIV TESTING CAMPAIGNS: AN IMPORTANT STRATEGY FOR THE EXPANSION OF EARLY DIAGNOSIS IN THE STATE OF SAO PAULO, BRAZIL - SIX CAMPAIGNS - TWO MILLION TESTES PERFORMED FROM 2008 TO 2016}

Karina Wolffenbuttel, Márcia Fernandes Dos Santos, Tânia Regina Corrêa De Souza, Maria Aparecida Da Silva Maria Clara Gianna. STD/AIDS State Program, STD/AIDS Reference and Training Centre, São Paulo - SP, Brazil

10.1136/sextrans-2017-053264.352 